\title{
Capítulo 8 \\ YouTube y las nuevas estrategias de Comunicación Política
}

Narcisa Medranda Morales

Universidad Politécnica Salesiana, Ecuador

Orcid: https://orcid.org/oooo-ooo2-8191-9849

Luis Araneda Delgado

Universidad Politécnica Salesiana, Ecuador

DOI: https://doi.org/ 10.16921/ciespal.14.10

\section{Resumen}

Las nuevas tecnologías afectan la manera de hacer política y la comunicación política en sí. La llegada de los medios digitales y las redes sociales como YouTube han marcado un hito en ambos fenómenos. La política ha tenido que adaptarse a estos nuevos medios; sin embargo, en lo que se refiere a la comunicación política, no se utilizan en su máximo exponente. Los medios digitales tienen la capacidad de generar excelentes espacios para este tipo de comunicación, acercando a las partes involucradas y atrayendo a nuevas audiencias. Comunicadores, partidos políticos e instituciones públicas deben unir fuerzas para explotar al máximo estas plataformas, propiciando interacciones fructíferas útiles a mejorar aspectos de la vida política y pública en beneficio de la sociedad.

Palabras clave: YouTube; comunicación política; redes sociales; política.

\section{Abstract}

New technologies affect the way politics are made and political communication itself. The advent of digital media and social networks 
such as YouTube has been a milestone in both phenomena. Politics was forced to adapt to these new media; however, as far as political communication is concerned, they are not used to their full potential. The digital media have the capacity to generate excellent spaces for this type of communication, bringing the parties involved together and attracting new audiences. Communicators, political parties and public institutions must join forces to make the best use of these platforms, fostering fruitful interactions useful to improve aspects of political and public life for the benefit of society.

Keywords: YouTube; political communication; social networks; politics.

La política forma parte de la vida de una sociedad. Del mismo modo, los medios de comunicación han estado presentes desde los inicios y han evolucionado con ella. Esto se repite en todas las formas de comunicación, desde los medios impresos, los audiovisuales, como la radio y televisión, hasta los digitales, en donde se encuentran escritos, audios y audiovisuales que se han convertido en una parte imprescindible de la comunicación cotidiana, con carácter de entretenimiento, informativo, educativo o político. En este último grupo se encuentra la plataforma YouTube.

\section{Perspectiva histórica de la política}

Desde una perspectiva histórica, no cabe duda de que la comunicación y la política son actividades inherentes a la vida misma del ser humano, reconocido este como un ser social en esencia, tal como lo sentencia Aristóteles en su obra La Política. Afirma el filósofo estagirita que la capacidad del ser humano de comunicarse mediante el lenguaje lo distingue y vuelve un ser superior respecto de los otros animales. Pero, a su vez, esta condición de ser social lo obliga a vivir en la Polis, organización social que, en su estructura más desarrollada y actual, se conoce como el Estado. Precisamente, es con respecto a la CiudadEstado que el propio Aristóteles se refiere, desde hace más de 2.300 
años, a la comunicación o al modelo de comunicación que él llamó La Retórica, como "la búsqueda de todos los medios posibles de persuasión" (Beltrán, 2007, p.72).

Cuando los ciudadanos se comunican, utilizando la retórica, tienen como fin último convencer o persuadir a los demás con argumentos y razonamientos lógicos. Así, el acto de comunicar se vuelve un acto político y la retórica encuentra su campo de acción en la vida cotidiana y en la política. En la polis, por tanto, con el otro, se delibera. Es una práctica del hablar que discursa, que procede formulando premisas, para llegar a conclusiones lógicas y, en consecuencia, a decisiones para el hacer. Abrir la boca es para hacer algo juntos. (Domínguez, 2014, p.174)

Así entiende la política Aristóteles, como una actividad propia de los virtuosos, que mediante el buen uso del lenguaje y del discurso aporta a la construcción del bien común o del bien vivir.

Para comprender en toda su dimensión lo que hoy es la política como ciencia, dentro del Estado moderno, resulta ineludible revisar el pensamiento político de Nicolás Maquiavelo ${ }^{5}$. En su obra El Príncipe, escrita en 1513, el asesor y diplomático florentino se distancia diametralmente de la filosofía o ética política de Aristóteles, para pasar a diseñar con sus postulados el pragmatismo político. "Resulta evidente en El príncipe que no interesa directamente al autor el bien común ni cuál sea la organización del Estado (república o principado de cualquier tipo), mientras se encuentre bien ejercido el poder" (Schenoni, 2007, p.210). Se inaugura así la ciencia política moderna, que desde entonces se definirá como la actividad encaminada a la búsqueda y conservación del poder. Con Aristóteles y Maquiavelo queda configurado el deber ser y el ser de la política. Sin embargo, entre estas dos visiones opuestas, hay un punto de convergencia. Cuando "El primer pilar sobre el que se asienta todo proyecto político es, a ojos de Maquiavelo,

5 Diplomático, filósofo, político y escritor italiano, considerado padre de la Ciencia Política moderna. Vivió en Florencia entre 1469-1527. 
la búsqueda del apoyo popular" (Fernández de la Peña, 2016, p.83) y para conseguir ese apoyo resulta indispensable persuadir a los demás. Queda así establecido el vínculo indisoluble entre ciencia política y comunicación: persuadir, para alcanzar la adhesión de la multitud y, en conjunto, construir el bien común; pero también se necesita persuadir para conseguir la subordinación de los otros, mediante la conquista y ejercicio del poder político. Todo lo dicho explica en cierta medida la génesis de la comunicación política. Cierto es que los medios y formas de comunicar han evolucionado vertiginosamente; el lenguaje, la escritura, la imprenta, la radio, prensa, televisión y actualmente el Internet con las redes sociales, han representado un factor sustancial, en un determinado contexto histórico, para redefinir las estructuras del poder político y las interrelaciones sociales dentro de un Estado.

En la historia de la humanidad las revoluciones en la esfera de los medios de comunicación resultan más decisivas que las revoluciones en la esfera de los medios de producción. Estas últimas generan nuevas civilizaciones materiales; las primeras, en cambio, nuevos universos culturales (Ortiz y Álvarez, 2009, p.173). Esto explica por qué la ciencia política y la comunicación siempre han caminado de la mano en el tiempo. Desde luego, con el desarrollo de los medios masivos o mass media, este vínculo termina por consolidarse. A partir de la segunda mitad del siglo XX se comienza a hablar de la sociedad mediatizada. Toda acción e interacción humana está mediada y condicionada por los medios de comunicación masivos; los individuos, grupos, organizaciones y, por cierto, las grandes corporaciones, que se proponen captar y ejercer el poder político, encuentran en los mass media a sus mejores aliados. De allí su interés, no solo por acercarse a ellos, sino también por administrarlos e, incluso, controlarlos. 


\section{YouTube como espacio de difusión de la comunicación política}

La comunicación política va más allá de lo referente a las campañas políticas. El proceso de trasmitir la información relacionada a este ámbito debería ser una constante, en donde la ciudadanía, los actores políticos (gobiernos e instituciones públicas) y medios de comunicación transmitieran información de manera multidireccional sobre los asuntos públicos. La manera en la que se ha llevado a cabo la trasmisión de esta información ha evolucionado con el tiempo. Se pueden destacar tres grandes etapas.

- Etapa pre-moderna (hasta 1960). Marcada por una fuerte autonomía en cuanto a la información política para la difusión. Los mismos partidos o instituciones construyen la información que se difunde en los medios de la época: los diarios impresos, la radio y la televisión, la cual iniciaba sus actividades masivas. La información en esta etapa es unidireccional, ya que solo es recibida por la ciudadanía, sin la posibilidad de participar directamente en su difusión.

- Etapa moderna (1960-1995). En este período se genera un cambio en la autonomía de la comunicación política. La política adquiere un carácter más autónomo. Con la participación de los medios, se comienzan a trasmitir debates políticos e información más homogénea por partes de los partidos e instituciones políticas y públicas.

- Etapa posmoderna (1995-actualidad). Es un período de grandes cambios. Las Nuevas Tecnologías de la Comunicación e Información y, de manera particular, la llegada de Internet, han generado variaciones sustanciales en las formas de comunicar de los medios $\mathrm{y}$, por ende, en la comunicación política. Comunicar e informar es más fácil para cualquier ciudadano gracias la inmediatez de la información y la interacción social 
que provocan las redes sociales. La información llega más directamente a los ciudadanos, es recibida, modificada y enviada a otras personas en el mismo momento de la recepción.

En la actualidad, la masificación de la información en los espacios digitales y la presencia de la política en estos medios han llegado a generar tal impacto en la sociedad que se han acuñado términos para la comunicación política como ciberpolítica, ciberdemocracia y prosumidor, entendiendo a este último como aquel que produce pero a su vez genera contenido e información. De este modo, se puede entender la comunicación política como "un proceso interactivo que involucra la transmisión de información entre políticos, medios de comunicación y votantes" (Norris, 2002, p. 127).

La ciberpolítica se refiere a nuevas formas de interacción entre el gobierno y los ciudadanos, entre estos y los partidos políticos, las empresas, los órganos legislativos y los ciudadanos de un régimen político y entre ciudadanos del mundo, permitiendo entre las personas y las personalidades políticas una relación más estrecha. No solo los medios de comunicación se encargan de difundir información más profesional. Los partidos e instituciones públicas y políticos también se dan la tarea de conocer a sus ciudadanos, presentar información más coherente, ordenada y adaptada al público que la va a recibir, además de establecer una relación más cercana entre ellos, rompiendo un poco con la convencional estructura político-ciudadano y otorgando a uno algo del rol del otro. Ahora el ciudadano también es un actor político, puede participar e influir directamente sobre los partidos o instituciones públicas; a su vez, estos se convierten también en ciudadanos, ya que no solo buscan influir en el otro grupo, sino que participan y co-crean la información en conjunto.

Al final de los años noventa se comienzan a ver las primeras webs creadas para candidatos y campañas políticas, con foros abiertos para que la ciudadanía participe y esté en contacto con el candidato y partidos políticos. Los blogs y micro blogs fueron los sucesores de 
los sitios web, en donde se puede ver no solo la información de los partidos o administraciones públicas, sino un perfil del candidato o de la institución, y conocer de más cerca y de forma más detallada la información. La llegada del video en redes sociales y en Internet es otro hito que marca una diferencia en la forma en la que la información es transmitida. La red que determina el punto de quiebre para la transmisión de la información es YouTube. Con su creación, en el año 2005, las personas tienen otra manera de ver y recibir la información, y el impacto de los videos que se ofrecen es mucho mayor que el de otras formas de comunicación. La plataforma permite la comunicación entre lo político (partidos, instituciones, candidatos) y la ciudadanía, y entre los mismos ciudadanos; posibilita el compartir la información a otras plataformas, lo que le da un potencial para hacerla viral y generar un impacto un gran impacto.

Actualmente, la plataforma cuenta con dos mil millones de usuarios. De acuerdo con Alexa (2010), YouTube revolucionó el panorama audiovisual. Si bien ya existían redes sociales, ninguna era capaz de rivalizar con el medio de comunicación tradicional, la televisión. Los debates políticos, reuniones, eventos u otro suceso que pueda ser grabado, está disponible para cualquier persona con acceso a Internet y un ordenador. Pero la gran diferencia entre la visualización en medios como la televisión y YouTube es el carácter más flexible y amplio de este para recibir la información y hacer uso de ella en el momento. Puede ser compartida o intervenida, es posible generar contenido escrito en la misma plataforma o compartirlo en otros medios que pueden ser vistos por otros, lo que trae como consecuencia el influir en otras personas. Otro aspecto importante es la perdida de exclusividad de los medios de comunicación tradicionales en el trabajo de transmitir la información a los ciudadanos. Las instituciones públicas, partidos o candidatos, con la creación de sus canales, hablando particularmente de YouTube, pueden crear y gestionar sus contenidos de manera independiente y hacerlo llegar a quien sea de interés, sin la necesidad de pasar necesariamente por los medios de comunicación tradicionales. 
Un ejemplo claro, que marcó un hito en la historia de la comunicación política, es el caso de Barack Obama y su campaña para postularse como presidente en 2008. El video Yes, we can se hizo viral y fue un factor determinante para su elección a la presidencia de Estados Unidos. El video muestra cómo el candidato está acompañado de artistas, influenciers, otros actores que se deben considerar al momento de hablar de la comunicación en redes sociales y particularmente de YouTube.

\section{Figura 1. Campaña de Obama para la presidencia de los Estados Unidos}

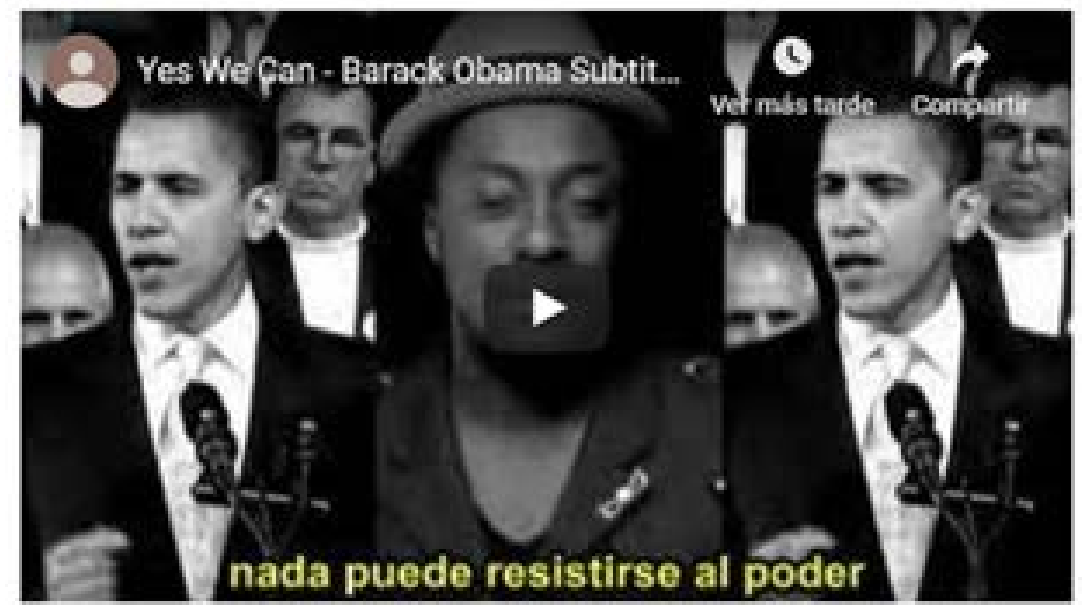

Fuente: WIKIALICE (2020). Diccionario Enciclopédico de la Comunicación Política

En las redes sociales, los influencers son personas que tienen presencia e influencia y pueden estar en diferentes plataformas. Suelen caracterizarse por tener gran cantidad de seguidores (aunque esto no es totalmente determinante para el impacto que tienen, depende de qué tan orgánicas sean sus comunidades) y tienen la capacidad de mover masas mediante el llamado a la acción, preguntas o simplemente 
por el impacto que tienen al ser reconocidos por gran cantidad de personas. En el contenido que comparten expresan ideas y opiniones, característica que se aplica también al ámbito de la política. Lewis (2017) menciona que un influencer es aquella persona con la capacidad de influir e, incluso, cambiar los comportamientos de un público específico en un contexto determinado.

Un factor a favor de YouTube es su posibilidad de atraer e involucrar los jóvenes en la política. Tan solo para el 2017, el 72\% de los jóvenes reconoce que prefiere consumir contenido de esta plataforma por sobre otras, por la libertad que le ofrece de elegir el contenido de preferencia e interactuar con otros usuarios. Si se considera la población votante que suele estar más ligada al ámbito político y la vida pública, resulta que 8 de cada 10 personas entre 18 y 49 años ingresan en YouTube. Solo en el 2015 este grupo de persona pasó un 4\% menos viendo televisión, eligiendo esta plataforma como opción. Los ciudadanos de 50 años en adelante también se suman de manera progresiva al consumo de este tipo de plataformas. Con respecto a la población que aún no tiene la edad para votar, pero que es gran consumidora de contenido de YouTube, el uso de la plataforma es útil para la formación de criterios y opiniones que, luego, definirán tendencias en su forma de hacer política, como ciudadanos, y en la forma de relacionarse con los políticos, las instituciones públicas y otros ciudadanos.

\section{El contenido de la comunicación política en YouTube}

En el caso del consumo de contenido dentro delámbito político, el mayor porcentaje de visitas es registrado por los videos que tienen carácter de infoentretenimiento, muy efectivos para captar la atención de la audiencia hacia la información apelando a las emociones y sensaciones. La intención de este tipo de productos audiovisuales es otorgar un tono más ligero a la transmisión de información de carácter político y entretener al espectador utilizando el recurso del sensacionalismo. Si 
bien el infoentretenimiento tiene el objetivo de causar mayor impacto en los consumidores de información, una de sus características o consecuencias es que el contenido es presentado de manera más simple, con lo que pierde profundidad e impacto al momento de ser utilizado para generar cambios en las agendas públicas. El infoentretenimiento por lo general muestra a actores políticos hablando de asuntos de su vida $u$ otros aspectos banales. Se suele presentar mediante la exposición de escenarios en donde frecuentemente se ven y escuchan insultos, agresiones y otros comportamientos considerados inapropiados, en especial para las personas que involucradas en ellos.

Según datos obtenidos por Rodríguez-Breijo, Gallardo-Camacho y Sierra-Sáncez. (2018), alrededor del 75 \% del contenido relacionado con política viene de fuentes anónimas o poco conocidas. La mayoría de estos contenidos presentan voz en off, información ofrecida mediante subtítulos o mediante la utilización de voces automatizadas, personas no identificadas o algún tipo de edición amateur. Dentro de todo el contenido publicado en esta plataforma, que tiene como objeto la política, solo un $60 \%$ tiene referencias a fuentes confiables. Para que la información tenga mayor confiabilidad, calidad e imparcialidad, en especial cuando tiene carácter político, es necesario que considere la opinión de todas las partes involucradas. Según los autores, esto sucede solo en un $20 \%$ de las ocasiones, mientras que el $70 \%$ de las veces que se transmite una información solamente se expresa la postura de una de las partes, y en el 10\% restante no se presentan partes en conflicto. La mayoría de este contenido es tomado de material emitido por medios de comunicación y reproducido en la plataforma sin ulterior edición.

Sin embargo, no todo el contenido que se reproduce en YouTube tiene que ver con el entretenimiento. En la plataforma también se encuentra contenido de carácter informativo y con un tono más profesional y periodístico. Este tipo de contenido, por lo general, es compartido por medios de comunicación o canales administrados por partidos políticos, organizaciones públicas o relacionadas al ámbito, aunque con menor presencia respecto a otro tipo de cometido político. 
Los videos informativos se constituyen con un espacio de debate y confrontación política. Aun cuando no se cuente con opiniones o debates sustentados con argumentos válidos, donde las emociones prevalecen sobre las razones, existe interacción entre diferentes entes involucrados. Por este motivo, YouTube es considerada como una herramienta con mucho potencial, fácil de utilizar y eficaz para a comunicación con los públicos de la política, mediante la cual se pueden crear espacios para un debate verdaderamente productivo para la sociedad.

Si bien la plataforma tiene como fin entretener y hacer llegar el contenido a más gente, es importante que se considere también la calidad de la información presentada, en particular cuando se trata de temas políticos, de interés público y ciudadana. YouTube resulta muy eficaz para motivar el público a interesarse por los asuntos políticos y ciudadanos. En tal sentido, es importante velar por la calidad de la información consumida por la audiencia objetivo de la comunicación política, sobre todo por la gran cantidad de "información basura" o fake news que pueden confundir o distorsionar la percepción que los ciudadanos generan como resultado del consumo de videos en la plataforma. Este problema no es exclusivo de YouTube y plantea una tarea desafiante para los profesionales de la comunicación política y la comunicación en general: guiar los públicos hacia los contenidos preparados para ellos. De este modo, los ciudadanos pueden hacer mejor uso de los contenidos y participar de manera más provechosa en los asuntos que le conciernen. Además, las nuevas audiencias conformadas principalmente por el público más joven aún están formando una opinión política, por lo cual resulta fundamental ofrecer información de calidad con una visión general y holística de los temas. Como consecuencia, tendrán la oportunidad de formar opiniones válidas, útiles para su futuro de ciudadanos activos. Si la información y opinión que se ofrece es sesgada, pierden valor y la ciudadanía perderá fuerza al momento de exigir mejores condiciones. 
Ante esto, los expertos comunicadores tienen un reto que afrontar. Es cierto que la plataforma está diseñada para que la ciudadanía y las personas puedan subir contenido de cualquier índole, ya sea de carácter formal y periodístico o de entretenimiento. Pero es importante que se tome en cuenta que la información política, para las personas involucradas o no en ella, tiene como finalidad dar a la ciudadanía herramientas para que puedan mejorar su calidad y condición de ciudadanos. Los medios de comunicación y organizaciones políticas o de carácter público deben presentar la información de forma correcta y con la debida transparencia. Kovach y Rosenstiel (2012) hacen énfasis en que la información útil debe ser trasparente. Para esto, debe estar disponible, verificada, ser útil, vigente al momento de ser presentada, de fácil entendimiento y uso para quien la consume. De igual forma, es importante entender que la manera de presentar y consumir información ha cambiado con la aparición de las redes y plataformas digitales. Actualmente, la información creada de manera profesional convive con la información de carácter amateur, generada por la audiencia. Por este motivo, es importante que los medios, partidos políticos y entes públicos se avoquen a la tarea de estar cada vez más presentes en estos nuevos espacios.

Tanto los medios como las organizaciones públicas deben explotar más el potencial de YouTube. Si bien la plataforma permitelainteracción con los ciudadanos y la participación entre ellos, la participación entre los responsables de las agendas públicas y la ciudadanía es menor. Este espacio de interacción acerca a las partes y genera un clima de confianza e igualdad que debe saber ser aprovechado para mejorar el resultado de la comunicación entre ciudadanía y entes públicos y, por ende, el de las agendas públicas. Si la información presentada en estos medios es transparente y adecuada, tendrá un impacto positivo en la agenda pública y favorecerá la democracia, uno de los fines de la información transparente. Los medios de comunicación siguen teniendo un papel protagónico al momento de informar sobre asuntos políticos. Si bien el consumidor tiende a ver cada día más diversos contenidos en YouTube, 
la información política, la información con carácter transparente y en definitiva de mayor utilidad, sigue siendo presentada en los medios tradicionales, en canales relacionados con estos medios o ligados a los entes públicos involucrados. Sumado a esto, la escasa interacción que actualmente se da entre los actores políticos y la ciudadana (aunque si bien es mayor que en otros momentos) no ha alcanzado un punto donde pueda desplazar a los medios tradicionales.

Otro de los retos a los que deben enfrentarse los encargados de la comunicación en redes y en la plataforma de YouTube, bien sean comunicadores al servicio de medios tradicionales o como parte del equipo de entes públicos, es constituido por la investigación. Aunque este fenómeno de la comunicación política en las plataformas digitales es reciente, resulta importante estudiar y analizar este fenómeno y obtener luces en cuanto a mejores estrategias para abordar e implementar en la comunicación política. Dentro de los temas de investigación, es notable la escasa cantidad de investigaciones sobre la comunicación política a través de las redes y plataformas digitales, escasez que resalta sobre todo en los autores de Latinoamérica; la mayor cantidad de estudios es realizada en países europeos como España. Esto da una idea del fenómeno comunicacional y su relación con la posición democrática y el carácter ciudadano en ambas regiones.

\section{El reto de la transformación}

La comunicación política es relevante para el buen uso y rendición de cuentas de los entes públicos. La manera en que esta se lleva a cabo y los medios utilizados tienen o deberían tener y tratarse con la misma importancia. Actualmente, en una era digital y de redes sociales, donde la mayoría de los consumidores de información y entretenimiento utilizan plataformas como YouTube, la comunicación política debe pasar por un proceso de transformación y adaptación. 
Aunque si bien progresivamente los new media han restado protagonismo a los medios tradicionales como la televisión, en el caso particular de la comunicación política y YouTube no se utiliza el máximo potencial. Se debe asumir el reto de promover la utilización de estos espacios que acercan ciudadanos y entes públicos de tal manera que la información publicada y disponible pueda dar como resultado mejor rendición de cuentas y manejo de agendas públicas. Además, su adecuado uso puede atraer nuevo público a interesarse por los temas políticos, categoría informativa en neto descenso entre los públicos objetivo.

Las partes involucradas deben unir fuerzas para sacar el máximo provecho de estas plataformas, propiciando interacciones fructíferas que posteriormente sirvan para mejorar aspectos de la vida política y pública para el beneficio común.

\section{Referencias}

Alexa. (2010). YouTube.com Competitive Analysis, Marketing Mix and Traffic. Recuperado de http://www.alexa.com/siteinfo/YouTube.com

Beltrán, L. (2007). Un adiós a Aristóteles: La comunicación "horizontal". Punto Cero, 12(15), 69-92. Recuperado de http://www.scielo.org.bo/scielo.php? script $=$ sci_arttext\&pid=S1815-02762007000200009\&lng=es\&tlng=es $\}$

WIKIALICE (2020). Diccionario Enciclopédico de la Comunicación Política [Medio utilizado]. https://www.bit.ly/2U2KZPZ

Fernández de la Peña, M. (2016). Los principios políticos en Maquiavelo. Entre el arte del Estado y la moral. Ingenium. Revista Electrónica de Pensamiento Moderno y Metodología En Historia De Las Ideas, 10, 75-91. Ediciones Complutense. doi: https://doi.org/10.5209/rev_INGE.2016.v10.54732

Kovach, B. y Rosenstiel, T. (2012). Los elementos del periodismo. Madrid: Aguilar Marketing Spain (2017). ¿Qué características debe tener un influencer? [Mensaje en un blog]. Recuperado de https://www.teamlewis.com/es/lewis-blog/ articles/caracteristicas-influencer 
Minguijón, J. y Pac, D. (2012). 15M. Una explicación en clave sociológica. Prisma social. Revista de Ciencias sociales. 8, 414-439. Recuperado de http://www. redalyc.org/pdf/3537/353744580014.pdf

Norris, P. (2002). Campaign communications. En L. Lee y C. Holtz-Bacha (Eds.), Encyclopedia of Political Communication (pp. 127-147). Los Angeles: Sage Publications.

Ortiz, R. y Álvarez, S. (Agosto de 2009). Globalización, tecnologías de la información y comunicación (TIC) en la Educación. En II Foro Internacional Derechos Humanos y Tecnologías de la Información y la Comuniación (TICS) en la Educación. México. Recuperado de https://www.repositoriodigital.ipn. $\mathrm{mx} /$ bitstream/123456789/3784/1/memorias2DHTIC_29.pdf

Rodríguez-Breijo, V., Gallardo-Camacho, J. y Sierra-Sánchez, J. (2018). Información política en los vídeos que son tendencia en YouTube España. El profesional de la información, 27(5), 1041-1049. Recuperado de http://www. elprofesionaldelainformacion.com/contenidos/2018/sep/o8.pdf

Schenoni, L. L. (2007). El concepto de lo político en Nicolás Maquiavelo. Andamios, 4(7), 207-226. Recuperado de http://www.scielo.org.mx/scielo.php?script=sci_arttext\&pid=S1870-00632007000200008\&lng=es\&tlng=es 
